\title{
ANALISIS PARTISIPASI WARGA MISKIN DALAM PERUMUSAN PERENCANAAN PEMBANGUNAN NAGARI DI NAGARI TANJUANG ALAM DAN NAGARI SUMANIK KABUPATEN TANAH DATAR TAHUN 2018
}

\author{
ANAL YSIS OF THE PARTICIPATION OF THE POOR PEOPLE IN THE \\ FORMULATION OF NAGARI DEVELOPMENT PLAN IN NAGARI TANJUANG \\ ALAM AND NAGARI SUMANIK, TANAH DATAR DISTRICT, 2018
}

\author{
Ari Ashadi1 1 ${ }^{*}$, Afrizal ${ }^{2}$, Rusda Khairati ${ }^{3)}$ \\ 1)*Mahasiswa Pembangunan wilayah dan Pedesaan Program Pascasarjana Unand, ari_124@yahoo.com \\ ${ }^{2)}$ Dosen Program studi Pembangunan wilayah dan Pedesaan \\ 3) Dosen Program studi Pembangunan wilayah dan Pedesaan
}

\begin{abstract}
ABSTRAK: Penelitian ini dilatar belakangi amanat Undang-Undang Nomor 25 tahun 2004 tentang Sistem Perencanaan Pembangunan Nasional (SPPN) dan Undang-Undang Nomor 6 Tahun 2014 tentang Desa yang mengamanatkan perlunya partisipasi masyarakat dalam perencanaan pembangunan termasuk partisipasi warga miskin. Penelitian bertujuan untuk mendeskripsikan ruang lingkup dan kedalaman partisipasi orang miskin dalam pembangunan nagari serta menganalisis proses penyelenggaraan perencanaan pembangunan nagari dalam pelibatan multistakeholder di Nagari Tanjuang Alam dan Nagari Sumanik Kabupaten Tanah Datar. Penelitian menggunakan metode penelitian kualitatif, dimana data primer yang bersumber dari responden menjadi data pokok untuk menjawab permasalahan yang dipertanyakan pada penelitian ini. Pengumpulan data dilakukan melalui wawancara mendalam terhadap informan kunci serta warga miskin di Nagari Tanjuang Alam dan Nagari Sumanik. Hasil penelitian menunjukkan bahwa ruang lingkup partisipasi masyarakat miskin dan proses penyelenggaraan perencanaan pembangunan nagari dalam pelibatan multistakeholder dalam perumusan perencanaan pembangunan nagari baik di Nagari Tanjuang Alam maupun di Nagari Sumanik telah sesuai dengan Permendagri 114 tahun 2014 tentang Pedoman Pembangunan Desa. Untuk kedalaman partisipasi orang miskin dari 9 (Sembilan) indikator terdapat 2 (dua) perbedaan antara nagari Tanjuang Alam dan Nagari Sumanik yaitu dilihat dari sisi cara keterlibatan warga miskin dan tingkat efektifitas partisipasi.
\end{abstract}

Kata Kunci: partisipasi, perencanaan, kemiskinan

ABSTRACT: This research is motivated by the Law Number 25 of 2004 concerning the National Development Planning System (SPPN) and the Law Number 6 of 2014 concerning Villages which mandates the need for community participation in development planning including the participation of the poor. The research aims to describe the scope and depth of participation of the poor in nagari development and analyze the process of nagari development planning in multi stakeholder engagement in Nagari Tanjuang Alam and Nagari Sumanik, in Tanah Datar District. The study uses qualitative research methods, where primary data sourced from respondents becomes the main data to answer the problems questioned in this study. Data collection was carried out through in-depth interviews with key informants and poor residents in Nagari Tanjuang Alam and Nagari Sumanik. The results showed that the scope of participation of the poor and the process of organizing nagari development planning in involving multi stakeholders in the formulation of nagari development planning both in Nagari Tanjuang Alam and in Nagari Sumanik were in accordance with Permendagri 114 of 2014 concerning Village Development Guidelines. For the depth of participation of the poor of the 9 (nine) indicators there are 2 (two) 
differences between the nagari Tanjuang Alam and Nagari Sumanik which is seen in terms of the way the poor are involved and the effectiveness level of participation.

Keywords: participation, planning, poverty

\section{A. PENDAHULUAN}

Partisipasi masyarakat dalam perencanaan pembangunan adalah amanat Undang-Undang Nomor 22 tahun 1999 sebagaimana telah diubah beberapa kali dan yang terakhir adalah Undang-Undang Nomor 23 tahun 2014 tentang Pemerintahan Daerah serta Undang-Undang Nomor 25 tahun 1999 yang juga telah mengalami perubahan menjadi Undang-Undang Nomor 33 tahun 2004 tentang Perimbangan Keuangan Pemerintah Pusat dan Daerah serta UndangUndang Nomor 25 tahun 2004 tentang Sistem Perencanaan Pembangunan Nasional (SPPN) mengamanatkan keperluan partisipasi masyarakat dalam perencanaan pembangunan. Kemudian Undang-Undang Nomor 6 Tahun 2014 tentang Desa juga mengamanatkan hal yang sama dimana perencanaan pembangunan desa diselenggarakan dengan mengikutsertakan masyarakat desa.

Conyers (1981) mengemukakan 3 alasan utama mengapa partisipasi masyarakat dalam perencanaan pembangunan sangat penting. Pertama, partisipasi masyarakat merupakan suatu alat untuk memperoleh informasi mengenai kondisi, kebutuhan dan sikap masyarakat setempat. Kedua, masyarakat akan lebih mempercayai program kegiatan pembangunan apabila mereka dilibatkan dalam persiapan dan perencanaanya, karena mereka akan lebih mengetahui seluk beluk program kegiatan tersebut dan akan mempunyai rasa memiliki terhadap kegiatan tersebut. Ketiga, mendorong partisipasi umum karena akan timbul anggapan bahwa merupakan suatu hak demokrasi bila masyarakat dilibatkan dalam pembangunan. Dari pandangan Conyers tersebut, partisipasi warga miskin dalam perencanaan pembangunan akan memberikan masukan bagi perencana pembangunan tentang kebutuhan orang miskin

Salah satu tujuan pembangunan di Indonesia adalah mengurangi angka kemiskinan. Warga miskin dengan segala keterbatasan yang dimilikinya memiliki hak yang sama untuk berpartisipasi dalam perencanaan pembangunan nagari. Berdasarkan pandangan Coyers diatas, partisipasi warga miskin dalam perencanaan pembangunan memberikan masukan bagi perencana pembangunan tentang kebutuhan orang miskin.

Riyadi dan Bratakusumah (2004) mendefinisikan perencanaan pembangunan sebagai suatu tahapan awal proses pembangunan yang akan dijadikan pedoman / acuan / dasar bagi kegiatan pembangunan. Sifat implementatif (dapat melaksanakan) dan sifat aplikatif (dapat diterapkan), disusun melalui perencanaan srategis (tidak terlalu mengatur, penting, mendesak dan menyentuh kehidupan masyarakat luas), mampu mengantisipasi tuntutan perubahan internal dan eksternal serta disusun berdasarkan fakta di lapangan merupakan kondisi ideal dari perencanaan pembangunan itu sendiri.

Undang-undang Nomor 25 tahun 2004 tentang SPPN menjelaskan ada 4 tahap proses perencanaan pembangunan yaitu : Tahap Penyusunan Rencana, Penetapan Rencana, Pengendalian Pelaksanaan Rencana Pembangunan, Evaluasi Pelaksanaan Rencana. Berkaitan dengan langkah ketiga tahap pertama proses perencanaan pembangunan, idealnya perencanaan pembangunan di desa / nagari adalah perencanaan pembangunan yang melibatkan seluruh lapisan masyarakat tanpa terkecuali mulai dari elit pemerintah nagari, Badan Permusyawaratan Rakyat Nagari (BPRN), Kerapatan Adat Nagari (KAN), Lembaga Pemberdayaan Masyarakat (LPM), Lembaga Unsur Nagari, PKK Nagari, Bundo Kanduang Nagari, FKPM, LINMAS, BKMT Nagari, Kader Pemberdayaan Nagari, Kader Posyandu/Paud/BKB Nagari, Badan Usaha Milik Nagari (Bumnag), Kelompok Tani dan Kelompok Wanita Tani (KWT), tokoh masyarakat, kaum difabel, kelompok masyarakat miskin dan kelompok-kelompok masyarakat lainnya. Dalam penyusunan dokumen perencanaan tersebut, sesuai dengan Permendagri nomor 114 tahun 2014 tentang Pedoman Pembangunan Desa juga disebutkan bahwa dalam penyusunan dokumen RPJM dan RKP Nagari dibentuk tim yang terdiri dari Wali Nagari 
selaku pembina, Sekretaris Nagari selaku ketua, ketua lembaga pemberdayaan masyarakat (LPM) selaku sekretaris, anggota yang berasal dari perangkat nagari, lembaga pemberdayaan masyarakat, kader pemberdayaan masyarakat Desa, dan unsur masyarakat lainnya dengan jumlah minimal 7 orang dan maksimal 11 orang.

Penggalian gagasan melalui musyawarah jorong dan musyawarah khusus oleh Tim dilakukan secara partisipatif dengan melibatkan seluruh unsur masyarakat. Secara mekanisme yang ada dalam konteks partisipasi kelompok masyarakat miskin, pemerintah secara implisit dalam legal formal yang ada telah mengakui keberadaan dan arti penting kebutuhan hidup mereka yang patut diperjuangkan dalam forum-forum formal seperti musrenbang. Kelompok masyarakat miskin sudah sepantasnya dijadikan arusutama (mainstream) dalam proses penggalian gagasan. Untuk menggali gagasan tentunya mereka juga ikut dihadirkan dalam forum-forum diskusi di tingkat jorong dan nagari. Metode dan cara untuk menghadirkan kelompok masyarakat miskin tentunya perlu juga diperhatikan oleh elit pemerintah nagari. Sebab, kerap masyarakat miskin menganggap kegiatan-kegiatan seperti rapat dan diskusi merupakan kegiatan yang "tidak pantas" bagi mereka. Mereka cenderung menggantungkan ide, gagasan mereka kepada "orang-orang berpengaruh" di tingkat jorong atau nagari seperti kepala jorong atau tokoh-tokoh masayarakat.

Hasil penggalian gagasan oleh Tim RPJM Nagari dan Tim RKP Nagari diserahkan kepada Wali Nagari selaku eksekutif di pemerintahan nagari untuk dilaksanakan Musyawarah Rencana Pembangunan (Musrenbang RPJM dan Musrenbang RKP). Dalam Musrenbang tersebut, kelompok masyarakat miskin diwakilkan dengan perwakilannya dalam rangka mengawal program / kegiatan yang telah diusulkan yang tertampung dalam RKP Nagari. Artinya proses perencanaan partisipatif khususnya dari kelompok miskin tidak terputus mulai dari penggalian gagasan sampai gagasan tersebut dibahas dalam forum musyawarah di tingkat nagari. Bedanya di forum tingkat nagari yang diundang bukan lagi kelompok miskin, namun merupakan perwakilan kelompok masyarakat miskin. Perwakilan kelompok miskin inilah nantinya yang ikut memperjuangkan aspirasi kelompoknya dalam penetapan skala prioritas kegiatan dalam Musrenbang RKP.

Secara mekanisme yang ada dalam konteks partisipasi kelompok masyarakat miskin, pemerintah secara implisit dalam legal formal yang ada telah mengakui keberadaan dan arti penting kebutuhan hidup mereka yang patut diperjuangkan dalam forum-forum formal seperti musrenbang. Kelompok masyarakat miskin sudah sepantasnya dijadikan arusutama (mainstream) dalam proses penggalian gagasan. Untuk menggali gagasan tentunya mereka juga ikut dihadirkan dalam forum-forum diskusi di tingkat jorong dan nagari. Metode dan cara untuk menghadirkan kelompok masyarakat miskin tentunya perlu juga diperhatikan oleh elit pemerintah nagari. Sebab, kerap masyarakat miskin menganggap kegiatan-kegiatan seperti rapat dan diskusi merupakan kegiatan yang "tidak pantas" bagi mereka. Mereka cenderung menggantungkan ide, gagasan mereka kepada "orang-orang berpengaruh" di tingkat jorong atau nagari seperti kepala jorong atau tokoh-tokoh masayarakat.

Berdasarkan identifikasi masalah penelitian diatas, pertanyaan penelitian yang ingin dijawab dalam penelitian ini adalah :

1. Bagaimana ruang lingkup dan kedalaman partisipasi orang miskin dalam pembangunan nagari?

2. Bagaimana proses penyelenggaraan perencanaan pembangunan nagari dalam pelibatan multistakeholder

\section{B. METODE PENELITIAN}

Penelitian ini dilaksanakan di Nagari Tanjuang Alam Kecamatan Tanjuang Baru, Kabupaten Tanah Datar dan Nagari Sumanik, Kecamatan Salimpaung, Kabupaten Tanah Datar dengan metode yang digunakan adalah metode penelitian kualitatif. Informasi data penelitian di ambil dengan cara wawancara mendalam pada Informan kunci penelitian yang terdiri dari : Wali Nagari, Pendamping Lokal Desa, Kepala Jorong' Masyarakat Miskin. 
Sumber data dalam penelitian ini adalah data kualitatif yang diperoleh melalui dari dokumen, informan (wawancara) dan hasil observasi. Untuk membedakan data berdasarkan jenisnya, data dibagi menjadi data primer dan data sekunder. Data primer merupakan data yang langsung dikumpulkan pada saat melaksanakan penelitian di lapangan berupa rekaman wawancara, pengamatan langsung melalui komunikasi yang tidak secara langsung tentang pokok masalah

Menurut Afrizal (2016) salah satu teknik pengumpulan data yang lazim digunakan oleh peneliti dalam penelitian kualitatif adalah wawancara mendalam (in-depth interview). Agar makna konsep wawancara mendalam dapat dipahami secara baik menurutnya wawancara mendalam adalah suatu wawancaa tanpa alternatif pilihan jawaban dan dilakukan untuk mendalami informasi dari seorang informan yang dilakukan secara berulang-ulang.

\section{HASIL DAN PEMBAHASAN}

\section{Gambaran Umum Nagari Tanjuang Alam}

Nagari Tanjuang Alam adalah salah satu Nagari di Kecamatan Tanjuang Baru, Kabupaten Tanah Datar yang terletak pada $0^{\circ} 17$ ' 35" $-0^{\circ} 21$ ' 51' 'Lintang Selatan dan $100^{\circ} 28^{\prime} 52$ " $-100^{\circ} 35^{\prime} 17^{\prime}$ 'Bujur Timur dan terletak di bagian utara Kabupaten Tanah Datar. Wilayah Nagari Tanjuang Alam berada pada 735 - 1.139 meter diatas permukaan laut (M.dpl). Nagari Tanjuang Alam, sebelah utara berbatasan dengan Kabupaten Agam, sebelah selatan dengan Kecamatan Salimpaung, sebelah barat dengan Kabupaten Agam dad sebelah timur dengan Kabupaten 50 kota.

Wilayah Nagari Tanjuang Alam terdiri dari dataran dengan luas sekitar $\pm 31.81 \mathrm{Km}^{2}$ atau 3.181 Ha yang terdiri dari : jorong gunung $\left(6,50 \mathrm{Km}^{2}\right)$, jorong koto laweh $\left(6,8 \mathrm{Km}^{2}\right)$, jorong sawah parik $\left(1,99 \mathrm{Km}^{2}\right)$, jorong bayua $\left(1,13 \mathrm{Km}^{2}\right)$, jorong Gantiang Ateh $\left(2,28 \mathrm{Km}^{2}\right)$, jorong koto gadih $\left(1,68 \mathrm{Km}^{2}\right)$, jorong gantiang bawah $\left(2,43 \mathrm{Km}^{2}\right)$, jorong duo baleh koto $\left(1,70 \mathrm{Km}^{2}\right)$, jorong koto sibauk $\left(1,83 \mathrm{Km}^{2}\right)$, jorong tarok $\left(1,42 \mathrm{Km}^{2}\right)$, jorong bulaan $(1,05$ $\left.\mathrm{Km}^{2}\right)$, jorong ampaleh $\left(3,22 \mathrm{Km}^{2}\right)$. Topografinya terdiri dari daratan, perbukitan dan pegunungan.

Kepadatan penduduk Nagari Tanjuang Alam tahun 2017 rata-rata adalah 253,97 jiwa / $\mathrm{Km}^{2}$ dengan jumlah penduduk Nagari Tanjuang Alam tahun 2016 berjumlah 8.072 jiwa terdiri dari 3.945 jiwa berkelamin laki-laki dan 4.127 jiwa berkelamin perempuan, tahun 2017 berjumlah 8.079 jiwa terdiri dari 3.952 jiwa kelamin laki-laki dan 4.126 jiwa berkelamin perempuan. Sebahagian besar penduduk Nagari Tanjuang Alam bergantung pada sektor pertanian, tanaman pangan, perikanan dan perdagangan. Sementara sumber daya potensial lainnya adalah pariwisata dan perkebunan.

\section{Hasil Penelitian}

Berdasarkan ruang lingkup partisipasi antara Nagari Tanjuang Alam dan Nagari Sumanik hasil penelitian ini menunjukan bahwa :

a. Partisipasi warga miskin dalam proses pembuatan keputusan di Nagari Tanjuang Alam dan Nagari Sumanik terdiri dari penggalian gagasan penyusunan dokumen RPJM Nagari, pencermatan ulang dokumen RPJM Nagari dalam rangka penentuan skala prioritas kegiatan di jorong dan rapat sosialisasi kegiatan dengan hasil sebagai berikut :

a) Penggalian gagasan dokumen RPJM Nagari Tanjuang Alam tahun 2017-2023 dan penyusunan dokumen RKP Nagari di 3 Nagari umumnya dihadiri seluruhnya oleh tokoh-tokoh masyarakat dan diantara tokoh-tokoh masyarakat tersebut terdapat beberapa yang tercatat sebagai penerima bantuan dan terdaftar dalam data BDT Dinas Soaial Kabupaten Tanah Datar.

b) Penggalian gagasan dalam penyusunan dokumen RPJM Nagari Tanjuang Alam tahun 2017-2023 dan penyusunan dokumen RKP Nagari di 3 Nagari umumnya dihadiri 
seluruhnya oleh tokoh-tokoh masyarakat dan diantara tokoh-tokoh masyarakat tersebut terdapat beberapa yang tercatat sebagai penerima bantuan dan terdaftar dalam data BDT Dinas Soaial Kabupaten Tanah Datar.

c) Penggalian gagasan dalam penyusunan dokumen RPJM Nagari Sumanik tahun 20172023 dan penyusunan dokumen RKP Nagari di 2 Nagari umumnya dihadiri oleh tokoh masyarakat dan terdapat rata-rata sekitar $40 \%$ warga miskin yang hadir dari seluruh jumlah peserta rapat.

d) Rapat sosialisasi kegiatan dan penyusunan TPK Jorong di Nagari Tanjuang Alam dan Nagari Sumanik umumnya sama yaitu warga miskin sangat antusias mengikuti rapat disebabkan karena dalam rapat tersebut disebutkan bantuan-bantuan yang akan masuk ke jorong termasuk bantuan- bantuan untuk warga miskin seperti rehab rumah miskin, pembangunan dan perbaikan drainase, pembukaan jalan usaha tani dan lain sebagainya.

e) Faktor pemilihan waktu rapat sangat berpengaruh terhadap kehadiran warga yang benar-benar miskin. Rapat yang dilaksanakan sesuadah sholat jum'at cenderung dihadiri oleh tokoh masyarakat saja sedangkan rapat yang dilaksanakan pada malam hari membuka peluang untuk warga miskin hadir.

b. Partisipasi warga miskin dalam keikutsertaan evaluasi dapat dilihat dalam bentuk pemberian kritik dan saran. Pemberian kritik dan saran oleh warga miskin baik di Nagari Tanjuang Alam maupun di Nagari Sumanik dilakukan secara lisan kepada kepala jorong dengan frekuensi yang sangat minim sekali. Hal tersebut disebabkan karena tidak terdapatnya kotak saran di masing-masing jorong.

Berdasarkan kedalaman partisipasi antara Nagari Tanjuang Alam dan Nagari Sumanik hasil penelitian ini menunjukan bahwa :

a. Untuk rapat penggalian gagasan RPJM dan rapat penyusunan dokumen RKP Nagari kedalaman partisipasi warga miskin dilihat dari tingkat keterlibatannya antara Nagari Tanjuang Alam dan Nagari Sumanik relatif sama yaitu berupa partisipasi yang dibangkitkan karena diundang secara resmi oleh Tim yang dibentuk oleh Pemerintah Nagari. Sementara kedalaman partisipasi dalam memberikan kritik dan saran baik di Nagari Tanjuang Alam maupun di Nagari Sumanik dikategorikan sebagai partisipasi spontan karena warga miskin memberikan kritik dan saran secara spontan tanpa permintaan dari Pemerintah Nagari.

b. Kedalaman partisipasi dilihat dari cara keterlibatan terdapat perbedaan yang mencolok antara Nagari Tanjuang Alam dan Nagari Sumanik. Partisipasi dalam pembuatan keputusan di Nagari Tanjuang Alam tergolong pada partisipasi tidak langsung sementara di Nagari Sumanik dapat digolongkan sebagai partisipasi langsung.

c. Kedalaman partisipasi warga miskin dilihat dari keterlibatan berbagai tahap proses perencanaan pembangunan baik di Nagari Tanjuang Alam maupun di Nagari Sumanik digolongkan sebagai partisipasi sebagian tahap karena tidak semua proses perencanaan dapat diikuti oleh Warga Miskin

d. Kedalaman partisipasi warga miskin dilihat dari tingkat organisasi baik di Nagari Tanjuang Alam maupun di Nagari Sumanik relatif sama yaitu merupakan partisipasi yang terorganisasi karena dilakukan secara terorganisir oleh Pemerintah Nagari.

e. Kedalaman partisipasi warga miskin dilihat dari intensitas partisipasi baik di Nagari Tanjuang Alam maupun di Nagari Sumanik dapat digolongkan sebagai partisipasi ekstensif karena intensitas musyawarah di tingkat jorong dilakukan tidak secara intensif atau dengan frekuensi yang tinggi.

f. Kedalaman partisipasi warga miskin dilihat dari kisaran aktivitas yang dapat dijangkau di Nagari Tanjuang Alam dan Nagari Sumanik umumnya adalah sama dimana untuk partisipasi dalam pengambilan keputusan kedalaman partisipasi dapat 
digolongkan sebagai partisipasi tidak terbatas sedangkan keikutsertaan memberikan kritik dan saran dapat digolongkan sebagai partisipasi terbatas. Dikatakan partisipasi tidak terbatas disebabkanseluruh usaha dapat dikontrol oleh anggota komunitas dalam hal ini adalah peserta rapat. Sementara digolongkan tidak terbatas karena kondisi pemberian kritik dan saran oleh warga miskin terbatas dan dipengaruhi oleh keadaan sosial ekonomi masyarakat khususnya warga miskin itu sendiri.

g. Kedalaman partisipasi warga miskin dilihat dari tingkat efektifitas terdapat perbedaan antara Nagari Tanjuang Alam dan Nagari Sumanik. Untuk partisipasi dalam pembuatan keputusan di Nagari Tanjuang Alam kedalaman partisipasi digolongkan sebagai partisipasi inefektif sementara di Nagari Sumanik dapat dikategorikan sebagai partisipasi efektif. Partisipasi efektif disebabkan karena tujuan pembangunan partisipatif yang melibatkan masyarakat miskin secara langsung di Nagari Tanjuang Alam tidak dapat tercapai secara optimal, sementara itu di Nagari Sumanik partisipasi efektif karena warga miskin yang hadir dalam rapat-rapat jorong murni karena status sosial sebagai warga miskin dan bukan karena status sosial lainnya sebagai tokoh masyarakat.

h. Kedalaman partyisipasi dilihat dari siapa yang berpartisipasi baik di Nagari Tanjuang Alam maupun di Nagari Sumanik sebagai partisipasi yang melibatkan anggota komonitas lokal dalam hal ini adalah warga asli dari Nagari Tanjuang Alam dan Nagari Sumanik itu sendiri.

i. Kedalaman partisipasi warga miskin dilihat dari tujuan dan gaya partisipasi baik di Nagari Tanjuang Alam maupun di Nagari Sumanik keduanya dikategorikan sebagai partisipasi dalam pembangunan daerah.

Pandangan Pusic (dalam Adi, 2001) diatas menekankan partisipasi masyarakat dalam pembangunan desa hanya pada tahap perencanaan dan pelaksanaan program pembangunan nampaknya belum lengkap guna menjamin kesinambungan pencapaian tujuan pembangunan desa. Hal ini sesuai dengan pendapat Adi yang melengkapi pandangan Pusic. Menurut Adi (2001) dalam hal partisipasi yang disampaikan Pusic diatas menganggap bahwa partisipasi belumlah cukup hanya melihat partisipasi masyarakat hanya pada tahapan perencanaan dan pelaksanaan saja. Partisipasi menurutnya hendaknya meliputi kegiatankegiatan yang tidak diarahkan (non direktif), sehingga partisipasi masayarakat meliputi proses-proses : (1) tahap Assesment, (2) tahap perencanaan alternatif program atau kegiatan, (3) tahap pelaksanaan (implementasi) program atau kegiatan, (4) tahap evaluasi (termasuk di dalamnya evaluasi input, proses, hasil).

Faktor penyebab partisipasi orang miskin dalam mengikuti rapat-rapat perencanaan pembangunan di Nagari Tanjuang Alam dan Nagari Sumanik terdapat perbedaan dimana jorong-jorong yang melakukan rapat setelah sholat Jum'at (Jorong Sawah Parik dan Jorong Koto Laweh) orang miskin yang hadir bukan mewakili diri mereka atas kemiskinan yang melekat pada diri mereka namun disebabkan karena status sosial lain yang melekat pada diri mereka seperti unsur ninik mamak, unsur cadiak pandai, bundo kanduang dan lain sebagainya. Sementara jorong-jorong yang melakukan penggalian gagasan setelah Sholat Isya (jorong Gunung, jorong Guguk Manih dan Jorong Piliang Sani) faktor penyebab partisipasi orang miskin hadir karena mereka adalah jamaah masjid yang setelah sholat Isya berkesempatan untuk duduk dan hadir mengikuti rapat perumusan perencanaan pembangunan nagari.

Dari hail penelitian di dapatkan bahwa penggalian gagasan dokumen RPJM Nagari Tanjuang Alam tahun 2017-2023 dan penyusunan dokumen RKP Nagari di 3 Nagari umumnya dihadiri seluruhnya oleh tokoh-tokoh masyarakat dan diantara tokoh-tokoh masyarakat tersebut terdapat beberapa yang tercatat sebagai penerima bantuan dan terdaftar dalam data BDT Dinas Soaial Kabupaten Tanah Datar. Partisipasi warga miskin dalam keikutsertaan evaluasi dapat dilihat dalam bentuk pemberian kritik dan saran. Pemberian 
kritik dan saran oleh warga miskin baik di Nagari Tanjuang Alam maupun di Nagari Sumanik dilakukan secara lisan kepada kepala jorong dengan frekuensi yang sangat minim sekali. Hal tersebut disebabkan karena tidak terdapatnya kotak saran di masing-masing jorong.

Abe (dalam Purnamasari, 2008) mengemukakan perencanaan dapat disebut partisipatif bila mencakup dua hal. Pertama perencanaan dikatakan partisipatif bila dalam tujuannya melibatkan kepentingan masyarakat. Kedua perencanaan partisipatif adalah perencanaan yang dalam prosesnya melibatkan rakyat (baik secara langsung maupun tidak langsung).

Proses dan mekanisme pelibatan multistakeholder di Nagari Tanjuang Alam dan Nagari Sumanik adalah sebagai berikut :

a. Proses perencanaan rapat di Nagari Tanjuang Alam dan Nagari Sumanik umumnya sama dimana untuk peserta rapat penggalian gagasan RPJM 2017-2023 telah mempedomani Permendagri 114 tahun 2014 tentang Pedoman Pembangunan Desa dimana pelibatan multistakeholder dalam rapat bersifat partisipatif yang melibatkan seluruh unsur masyarakat yang ada sesuai dengan kondisi sosial budaya yang ada.

b. Cara pelaksanaan rapat di Nagari Tanjuang Alam dan Nagari Sumanik telah berpedoman pada Permendagri 114 tahun 2014 relatif sama dimana rapat penggalian gagasan RPJM 2017-2023 dan rapat penyusunan dokumen APB Nagari rapat dilaksanakan diarahkan oleh Tim RPJM dan Tim APB Nagari yang di SK kan oleh Wali Nagari. Dalam pelaksanaan rapat dipandu oleh Pendamping Lokal Desa (PLD) dengan mempergunakan alat bantu kerja berupa sketsa nagari, kalendser musim dan bagan kelembagaan nagari. Sementara untuk cara pelaksanaan rapat pelaksanaan kegiatan yang terdapat dalam dokumen APB Nagari setelah disahkan oleh BPRN cara pelaksanaan rapat tidak seformal rapat penggalian gagasan RPJM dan penyusunan APB Nagari. Rapat hanya digagas oleh kepala jorong untuk mensosialisasikan kegiatan-kegiatan yang telah diakomodir dalam dokumen APB Nagari sekaligus membicarakan pelaksanaan gotong royong sebelum kegiatan dimulai.

c. Suasana Pelaksanaan rapat perumusan perencanaan pembangunan nagari di Nagari Tanjuanlg Alam dan Nagari Sumanik relatif sama dimana suasana rapat penggalian gagasan RPJM dan penyusunan dokumen APB Nagari bersifat formal dan terarah karena dimoderatori oleh Tim dari Pemerintah Nagari sedangkan rapat pelaksanaan kegiatan APB Nagari suasana rapat tidak formal dan hanya dimoderatori oleh kepala jorong.

d. Partisipasi aktif orang miskin dalam rapat perumusan perencanaan pembangunan Nagari di Nagari Tanjuang Alam (jorong Gunung) dan Nagari Sumanik (jorong Guguk Manih dan Jorong Piliang Sani) adalah cenderung diam dan tidak aktif dalam mengikuti rapat perumusan perencanaan pembangunan nagari.

e. Dalam pelaksanaan rapat perumusan perencanaan pembangunan nagari di Nagari Tanjuang Alam dan Nagari Sumanik kecenderungan didominasi oleh tokoh-tokoh masyarakat seperti unsur ninik mamak, cadiak pandai, alim ulama yang telah terbiasa berbicara dalam forum-forum formal tingkat jorong dan nagari.

Berdasakan hal diatas, maka dapat dilihat bahwa partisipasi yang dilakukan masyarakat bersama-sama pihak terkait lainnya dalam berbagai tahapan pembangunan akan menghasilkan konsensus dalam kebijakan pembangunan, dan sekaligus melatih masyarakat menjadi lebih pandai khususnya dalam penanganan masalah-masalah yang muncul di masyarakat. Selain manfaat tersebut menurut Suriana (dalam Laksana, 2013) terdapat 5 manfaat dari partisipasi masyarakat yaitu :

a. Partisipasi memperluas basis pengetahuan dan representasi

b. Partisipasi membantu terbangunnya transparansi komunikasi dan hubungan-hubungan kekuasaan di antara para stakholders

c. Partisipasi dapat meningkatkan pendekatan interatif dan siklikal dan menjamin bahwa solusi didasarkan pada pemahaman dan pengetahuan lokal. 
d. Partisipasi akan mendorong kepemilikan lokal, komitmen dan akuntabilitas. Pelibatan masyarakat lokal dapat membantu terciptanya hasil (outcomes) yang berkelanjutan dengan memfasilitasi kepemilikan masyarakat terhadap proyek dan menjamin bahwa aktivitas-aktivitas yang mengarah kepada keberlanjutan akan terus berlangsung. Hasil yang diperoleh dari usaha-usaha kolaboratif lebih mungkin untuk diterima oleh seluruh stakeholders.

e. Partisipasi dapat membangun kapasitas masyarakat dan modal sosial. Pendekatan partisipatif akan meningkatkan pengetahuan dari tiap stakeholders tentang kegiatan / aksi yang dilakukan oleh stakeholders lain.

Lebih jauh Syafrizal (2014) menyebutkan bahwa perencanaan tidak akan dapat meghasilkan pembangunan secara baik sesuai dengan aspirasi masyarakat bilamana tidak dapat mengoptimalkan partisipasi masyarakat dalam proses penyusunan rencana tersebut. Tanpa pemanfaatan partisipasi masyarakat secara baik dan terarah, perencanaan yang disusun tidak akan dapat disesuaikan dengan aspirasi dan keinginan masyarakat. Disamping itu, tanpa partisipasi masyarakat sulit pula diharapkan masyarakat akan mematuhi dan menjaga pelaksanaan rencana yang telah dibuat. Bahkan tidak jarang pula terjadi masyarakat tidak memanfatkan sepenuhnya apa yang telah dibangun oleh pemerintah. Karena itu, sangat tepat kiranya bilamana pendekatan Perencanaan partisipatif (participatory planning) merupakan alat yang tepat untuk dapat mengoptimalkan partisipasi masyarakat dalam perencanaan.

\section{PENUTUP}

Hasil penelitian menunjukkan bahwa ruang lingkup partisipasi masyarakat miskin dan proses penyelenggaraan perencanaan pembangunan nagari dalam pelibatan multistakeholder dalam perumusan perencanaan pembangunan nagari baik di Nagari Tanjuang Alam maupun di Nagari Sumanik telah sesuai dengan Permendagri 114 tahun 2014 tentang Pedoman Pembangunan Desa. Untuk kedalaman partisipasi orang miskin dari 9 (Sembilan) indikator terdapat 2 (dua) perbedaan antara nagari Tanjuang Alam dan Nagari Sumanik yaitu dilihat dari sisi cara keterlibatan warga miskin dan tingkat efektifitas partisipasi.

\section{F. DAFTAR PUSTAKA}

Adi, Isbandi Rukminto. 2001. Pemberdayaan, Pengembangan Masyarakat dan Intervensi Komunitas. Jakarta.: Lembaga Penelitian FE-UI.

Afrizal. 2016. Metode Penelitian Kualitatif : Sebuah Upaya Mendukung Penggunaan Penelitian Kualitatif Dalam Berbagai Disiplin Ilmu. Jakarta : PT. Raja Grafindo Persada

Conyers, Diana. 1994. Perencanaan Sosial di Dunia Ketiga : Suatu Pengantar. Yogyakarta : Gajah Mada University Press.

Riyadi dan Bratakusumah, D.S. 2004. Perencanaan Pembangunan Daerah, PT. Gramedia Pustaka Utama, Jakarta.

Undang-Undang Nomor 25 tahun 2004 tentang Sistem Perencanaan Pembangunan Nasional (SPPN).

Undang-Undang Nomor 22 tahun 1999 sebagaimana telah diubah dengan Undang-Undang Nomor 32 tahun 2004 tentang Pemerintahan Daerah.

Purnamasari, Irma. 2008. Studi Partisipasi Masyarakat Dalam Perencanaan Pembangunan Di Kecamatan Cibadak Kabupaten Sukabumi, Tesis, Universitas Dipenogoro, Semarang.

Sjafrizal. 2014. Perencanaan Pembangunan Daerah Dalam Era Otonomi. Jakarta: Rajawali Pers. 
Laksana, Nuring Septyasa. 2013. Bentuk-Bentuk Partisipasi Masyarakat Desa Dalam Program Desa Siaga Di Desa Bandung Kecamatan Playen Kabupaten Gunung Kidul Provinsi Daerah Istimewa Yogyakarta. Jurnal Kebijakan dan manajemen Publik, ISSN 2303$341 X$.

Permendagri 114 tahun 2004 tentang Pedoman Pembangunan Desa. 